\title{
Educação Especial e Inclusão Escolar: tramas de uma política em implantação
}

\author{
Rosângela Gavioli Prieto' \\ Karina Soledad Maldonado Molina Pagnez' \\ Roseli Kubo Gonzalez' \\ 'Universidade de São Paulo (USP), São Paulo/SP - Brasil
}

RESUMO - Educação Especial e Inclusão Escolar: tramas de uma política em implantação. Os objetivos deste trabalho são descrever e analisar a política de educação especial em curso no município de São Paulo, focalizando três dos sete projetos do Programa Inclui, criado em 2010. A análise, decorrente de fontes documentais, de encontros com profissionais de dois centros especializados, conduzidos nos moldes de grupo focal, e de entrevistas semiestruturadas com profissionais do sistema de ensino que atuam na área, mostra movimentos no município para instituir ações que subsidiem a permanência dos alunos nas classes comuns, pela via da ampliação das ações de suporte pedagógico, de formação específica e continuada e aumento do número de serviços e de agentes de inclusão escolar junto às escolas municipais.

Palavras-chave: Educação Especial. Inclusão Escolar. Gestão de Políticas Públicas.

\begin{abstract}
Special Education and School Inclusion: plots of a policy in construction. This work aims to describe and analyze the special education current policy in the city of São Paulo, focusing on three of the seven projects of Programa Inclui, created in 2010. The analysis, resulting from documentary sources (municipal legislation and official reports), meetings with professionals from two specialized centers, organized as focus groups, and semi-structured interviews with education professionals who work in this field indicates changes in the municipality to introduce actions that support the permanence of students in regular classes, by means of the expansion of pedagogical support actions, specific and ongoing training, and increase in the number of services and agents of school inclusion in São Paulo municipal schools.
\end{abstract}

Keywords: Special Education. School Inclusion. Public Policies Management.

Educação \& Realidade, Porto Alegre, v. 39, n. 3, p. 725-743, jul./set. 2014.

Disponível em: <http://www.ufrgs.br/edu_realidade> 


\section{Introdução}

A problemática deste artigo resulta de uma preocupação com a implementação de políticas municipais para a efetivação de propostas sustentadas em princípios da educação inclusiva. Para compreender as necessidades de sistemas de ensino públicos para a realização de seus objetivos, com destaque ao seu papel na garantia do provimento de serviços pedagógicos especializados, apoiamo-nos em autores como Jesus e Baptista et al. (2009), Baptista (2011), Mazzotta (1996; 2000), Mantoan (2001; 2003), Rodrigues (2006) Prieto (2011; 2006 apud Arantes, 2006). Esses autores discutem, em diferentes perspectivas, princípios, possibilidades e desafios para a execução de ações com vistas a propiciar a inclusão escolar de alunos com deficiência, transtornos globais do desenvolvimento (TGD) e altas habilidades/superdotação ${ }^{1}$.

Entre as ideias dos referidos autores, são apontadas intervenções de ordem legal e política e de ordem pedagógica para que os sistemas ou redes de ensino se reorganizem com o fito de atender demandas dos processos de escolarização desse alunado. Nas primeiras, constam normativas, planos de governo, programas e projetos criados para elevar as possibilidades de exercício e de ampliação de direitos desse público-alvo; nas segundas, formações, jornada de trabalho com horas de estudo e planejamento e outros investimentos visando a assegurar aos professores a apreensão e condições de adoção de conhecimentos que lhes permitam orientar sua prática na perspectiva da educação para todos, atingindo seus alunos em suas formas singulares de aprender. Além disso, ganham destaque nesse processo de constituição e consolidação de políticas de inclusão escolar a identificação e o provimento de serviços de caráter complementar ou suplementar, bem como de profissionais de apoio.

Neste artigo, são analisados aspectos da atual política de educação especial do município de São Paulo, sustentados na seguinte questão: quais ações foram propostas para favorecer a inclusão escolar mediante a complexidade de demandas emanadas da ampliação do ingresso desse alunado na classe comum?

Para responder a esta questão, são analisados resultados obtidos por uma pesquisa orientada pelos pressupostos da pesquisa-ação, que, para Miranda e Resende (2006, p. 511), “[...] articula a relação entre teoria e prática no processo mesmo de construção do conhecimento, ou seja, a dimensão da prática - que é constitutiva da educação - seria fonte e lugar privilegiado da pesquisa”.

Foram utilizadas fontes documentais tais como: legislação municipal, planilhas de dados e relatórios oficiais elaborados pela Rede municipal de ensino de São Paulo (RME-SP), além de enunciados extraídos de entrevistas semiestruturadas realizadas com gestores da educação especial em nível de sistema municipal de ensino. 
Outras importantes contribuições foram extraídas de gravações e de anotações feitas pelos pesquisadores nos encontros mensais de que participaram gestores de dois dos treze centros especializados paulistanos, aqui denominados Centro A e Centro B. Tais reuniões ocorreram de 2011 a meados de 2013 e tiveram como eixo para as reflexões a política de educação especial, das quais emanaram dados apresentados e discutidos.

Nos encontros com os gestores dos dois centros especializados, a indicação dos temas era previamente combinada e provinha das necessidades e inquietações dos participantes e, como pressupõe o uso dessa orientação metodológica, estes eram momentos utilizados, em particular, para a formação continuada dos participantes e produção do conhecimento (Ibiapina, 2008).

A entrevista semiestruturada foi realizada a partir de um roteiro organizado para permitir intervenções do pesquisador. Neste, havia a sinalização para a exploração do Programa Inclui (São Paulo, 2010), foco desta produção.

Excertos dos enunciados dos encontros foram transcritos em planilha com categorias organizadas a partir dos eixos da pesquisa e de outros focos de interesse que emergiram durante sua escuta.

Procedeu-se, em relação ao material documental, uma primeira leitura flutuante (Bardin, 2009) e outras sucessivas para identificar ideias determinantes dos sentidos da política. Os conteúdos das diferentes fontes foram reordenados e agrupados para, enfim, expressar os resultados ora apresentados.

Porém, faz-se necessário preparar o terreno para a compreensão das tramas enredadas para definir esses planos de ação a sua reconstituição a partir de atos normativos ainda em vigor.

\section{Educação Especial no Município de São Paulo: uma história em contínua construção}

A primeira iniciativa paulistana na área de educação especial ocorreu em 1951, quando foi criado o I Núcleo Educacional para Crianças Surdas, posteriormente intitulado Escola Municipal de Educação Infantil e de $1^{\circ}$ Grau de Deficientes Auditivos - Emeda Helen Keller (Prieto, 2000).

Todavia, apenas no final da década de 1980 e, principalmente, no início dos anos 1990 são localizados registros documentais com diretrizes que orientam a política municipal paulistana de educação especial pelo princípio da integração, propondo a sua constituição como apoio à escolarização de seu público-alvo matriculado em classe comum².

No final de 2004, por meio de dois instrumentos normativos: Decreto n. 45.415 (São Paulo, 2004a) e Portaria n. 5.718 (São Paulo, 2004b), a Secretaria Municipal de Educação de São Paulo - SME-SP - firmou 
sua política de educação especial para alunos "[...] cujas necessidades educacionais se relacionem com diferenças determinadas, ou não, por deficiências, limitações, condições e/ou disfunções no processo de desenvolvimento e altas habilidades/superdotação" a serem encaminhados para serviços de educação especial "após avaliação educacional do processo ensino-aprendizagem” (São Paulo, 2004a, art. 4º, p. 1).

As diretrizes da RME-SP, desde então, expressam que se deve dar primazia à matrícula desse alunado em classes comuns, garantindo-lhes todos os direitos extensivos aos demais alunos e atendimento educacional especializado, em conformidade com diretrizes e orientações nacionais ${ }^{3}$.

O Decreto n. 45.415 (São Paulo, 2004a, art. $3^{\circ}$, p. VIII) também cria os seguintes serviços para o atendimento desses alunos:

\begin{abstract}
Parágrafo único. Consideram-se serviços de Educação Especial aqueles prestados em conjunto, ou não, pelo Centro de Formação e Acompanhamento à Inclusão - CEFAI ${ }^{4}$, pelo Professor de Apoio e Acompanhamento à Inclusão $\mathrm{PAAI}^{5}$, pela Sala de Apoio e Acompanhamento à Inclusão - SAAI ${ }^{6}$, ora criados, e pelas 6 (seis) Escolas Municipais de Educação Especial já existentes.
\end{abstract}

Até o final de 2012, constava em documentos oficiais a existência de 13 centros especializados com 77 professores especializados itinerantes, 384 salas de recursos e seus professores regentes, seis escolas bilíngues para surdos e convênios de educação especial com aproximadamente 30 entidades ${ }^{7}$.

Os professores especializados itinerantes são profissionais da carreira do magistério que deveriam comprovar "especialização ou habilitação em Educação Especial” (São Paulo, 2004a, art. 6º p. 1). No entanto, o detalhamento das exigências de formação está presente em outro documento, com a definição de que cada centro especializado deve contar com "04 (quatro) Professores Titulares com especialização e/ou habilitação em Educação Especial, em nível médio ou superior, em cursos de graduação ou pós-graduação, preferencialmente um de cada área” (São Paulo, 2004b, art. 3º p. 15). Tal "módulo mínimo” de profissionais pode ser ampliado "excepcionalmente, desde que justificada a necessidade" por meio de solicitação de autorização por parte do diretor da Diretoria Regional de Educação e com a "anuência do Secretário Municipal de Educação” (São Paulo, 2004b, § 3º, p. 15).

Passados alguns anos de implantação dessas diretrizes, em 2009 foi realizado um estudo em âmbito da SME-SP por “[...] uma equipe intersetorial, designada como Comissão Especial de Trabalho, para realizar uma avaliação das ações [...] implantadas ao longo dos anos e [...] elaborar um plano de ação" (São Paulo, 2012a, p. 5) ${ }^{8}$.

Como um dos resultados do trabalho dessa comissão, consolida-se a atual política paulistana de educação especial por meio do Pro- 
grama Inclui, promulgado pelo Decreto n. 51.778 de 2010, que tem como propósito articular ações que visem ao "[...] acompanhamento da trajetória escolar e do processo de aprendizagem do aluno” (São Paulo, 2010, art. $1^{\circ}$, p. 1).

No art. $2^{\circ}$ deste Decreto, são apresentados os sete projetos do Programa Inclui, a saber: Identificar, Apoiar, Formar, Acessibilidade, Rede, Reestruturação das Escolas Municipais de Educação Especial e Avaliar. Os destaques a seguir incidem sobre três deles, que foram explorados neste trabalho, por serem os que tratam de aspectos fulcrais à política de educação especial:

II - Projeto Apoiar: ampliar as ações de suporte pedagógico especializado para o público-alvo da educação especial, por meio de:

a) instalação e manutenção das Salas de Apoio e Acompanhamento à Inclusão - SAAIs nas unidades educacionais da Rede Municipal de Ensino;

b) ampliação do módulo de Professor de Apoio e Acompanhamento à Inclusão - PAAI e designação de servidores incumbidos das atividades de apoio administrativo, para atuação nos Centros de Formação e Acompanhamento à Inclusão - CEFAIs, instalados em cada Diretoria Regional de Educação - DRE;

c) distribuição de estagiários nos CEFAIs para atuação nas unidades educacionais da região;

d) readequação dos convênios com instituições especializadas, de acordo com as diretrizes da Secretaria Municipal de Educação;

III - Projeto Formar: oferecer formação específica aos professores para atuação nos serviços de educação especial, bem como formação continuada aos profissionais de educação;

V - Projeto Rede: oferecer aos alunos matriculados nas unidades educacionais da Rede Municipal de Ensino, que apresentem quadros de deficiência e TGD, apoio intensivo na locomoção, alimentação e higiene para participação nas atividades escolares [...] (São Paulo, 2010, p. 1).

Este breve panorama sobre a política de educação especial no município de São Paulo pós 2004 nos revela a preocupação da SME-SP com o atendimento aos alunos desta modalidade de ensino por meio da inclusão escolar.

\section{Inclusão Escolar e Demandas de um Sistema Educacional: o Projeto Apoiar}

Consta no documento elaborado pela SME-SP/Diretoria de Orientação Técnica- Educação Especial (DOT EE), também intitulado Programa Inclui (São Paulo, 2012a) - cujo conteúdo se refere às ações desenvolvidas no quadriênio 2009-2012 - que essa secretaria já desenvolvia várias ações visando ao aprimoramento do atendimento ao público-al-

Educação \& Realidade, Porto Alegre, v. 39, n. 3, p. 725-743, jul./set. 2014

Disponível em: <http://www.ufrgs.br/edu_realidade> 
vo da educação especial no município de São Paulo desde 2005, portanto, antes de o Programa Inclui ser instituído. Um exemplo significativo foi a designação de professores especializados itinerantes ${ }^{9}$ para compor as equipes dos 13 centros especializados, número que aumentou a cada ano (32 designações de professores especializados itinerantes em 2009; 42 em 2010; 52 em 2011; e 66 em 2012) ${ }^{10}$.

Esses professores têm como atribuições: articular suas atividades com o projeto de trabalho estabelecido pelo Cefai; realizar atendimentos individuais ou em grupos no contraturno ou em colaboração com o professor da classe comum em horário de aula; propor, acompanhar e avaliar, juntamente com a equipe escolar, ações que auxiliem a inclusão escolar dos alunos público-alvo da educação especial; discutir com os profissionais da escola as práticas pedagógicas desenvolvidas; orientar as famílias dos alunos e manter registro de suas atividades (São Paulo, 2004b, art. $8^{\circ}$ ).

Os profissionais de dois centros especializados, por diversas vezes, relataram, ao menos em suas regiões, que a equipe era insuficiente para assumir todas essas atribuições arroladas ${ }^{11}$, às quais se somavam tarefas de cunho administrativo, que incluíam desde a preparação de todos os trâmites dos cursos de formação (formulação dos cursos, agendamento de local, preparação de listas, etc.) a, por exemplo, fazer o controle e envio de frequência de profissionais que atuavam em algumas escolas junto a alunos que requeriam apoio intensivo e contínuo ${ }^{12}$. Esse dado impõe ao município intervenções urgentes no sentido de tornar mais robustos os centros especializados, equacionando a demanda de intervenções com a composição das equipes.

No período, foi ampliado o número de salas de recursos, com a instalação de 24 em 2009, que se somaram às $152^{13}$ em funcionamento, totalizando 176; em 2010, foram acrescidas 134 salas $^{14} ; 47^{15}$ em 2011; e $26^{16}$ em 2012, totalizando $383^{17}$, sem contar as revogadas no período. Contudo, 20 dessas salas estavam sem professor, sendo que apenas uma apresentava o motivo - licença gestante - e informava não haver, à ocasião, professor disponível sequer para cobrir o período de afastamento justificado de regente de sala de recursos, o que diminuía o potencial da oferta de atendimento educacional especializado nesse município.

A Portaria n. 2.496, em seu art. 17 (São Paulo, 2012b), estabelece a atual regulamentação das atribuições dos professores das salas de recursos e os coloca como responsáveis por fomentar apoio por meio de visitas às classes comuns nas quais estão matriculados os alunos que frequentam o atendimento educacional especializado no contraturno ou promover a articulação de todos os docentes da escola para que esse alunado participe de todas as atividades escolares (São Paulo, 2012a, art. 17). Além disso, cabe a esse profissional orientar tanto docentes quanto familiares em relação aos recursos pedagógicos e de acessibilidade utilizados pelos alunos de modo a ampliar sua autonomia. 
Ainda, para Oliveira e Drago (2012, p. 356), o Projeto Apoiar deveria: “e) contratar e acompanhar a distribuição de 1000 (mil) estagiários de pedagogia nas salas de aula com o intuito de auxiliar o professor da sala regular e/ou dar assistência necessária nos atos de vida escolar (atividades curriculares, educativas, extraclasse entre outras)", para trabalhar junto ao Programa Inclui como agente da inclusão escolar, com sua formação continuada sob a responsabilidade da DOT-EE e dos centros especializados. De acordo com a Portaria n. 2.963 de 2013, suas atribuições são de auxiliar o professor da classe comum na preparação de atividades e assessorar o docente e alunos, individualmente ou em pequenos grupos, no desenvolvimento das atividades em sala de aula. Ressalte-se que essas atividades deveriam ser acompanhadas pelo coordenador pedagógico, professor regente da classe e equipe do Cefai (São Paulo, 2013, art. 4º).

Equipes gestoras dos dois centros especializados identificavam desvios de função. Não era incomum ouvir de estagiários, durante os encontros mensais de formação, relatos de que havia um movimento de pressão para que assumissem o aluno de inclusã $o^{18}$, responsabilizando-se por esse aluno durante todo o turno de aula.

No entanto, em entrevista com gestores da educação especial, a coordenadora da equipe atentou para possíveis ganhos com a contratação de estagiários. Para a profissional, apesar de todas as dificuldades, essa experiência na RME-SP propicia que levem "para dentro dos cursos também uma realidade que não era discutida nas universidades". Ainda, indica como outro efeito o fato de que "uma maioria permanece com a formação, porque eu tenho encontrado [esses alunos/estagiários] em [cursos] de Pós-graduação", e estes se tornam estudantes com mais conhecimento em formações administradas pelos centros especializados e, com isso, dirimem "ideias equivocadas de que eles tinham que cuidar desses alunos" e porque se abre uma possibilidade de "formar também novas gerações de professores" (Prieto et al., 2013).

Ademais, é preciso pontuar que o problema maior dessa estratégia é fazer com que reivindicações históricas de diminuição de número de alunos por turma e de contratação de um profissional como auxiliar do professor fiquem reduzidas a manter estudantes nas classes acobertando essas legítimas demandas do magistério.

Para Oliveira e Drago (2012, p. 356), esses estagiários devem receber orientações da equipe de educação especial do município sobre “[...] como agir no interior das escolas, ou seja, para que, realmente, sejam apoio à sala de aula e não exclusivamente ao aluno com necessidades educacionais especiais", sendo esta, portanto, a orientação principal e que constitui o maior desafio da proposição de esse agente atuar em algumas classes comuns. 


\title{
Sobre Acesso a Conhecimentos e a Inclusão Escolar: o Projeto Formar
}

De acordo com Oliveira e Drago (2012, p. 358, grifos dos autores),

\begin{abstract}
[...] o Projeto Formar tem o objetivo de proporcionar a formação permanente de toda equipe escolar, através de cursos de formação continuada em diferentes dimensões como cursos de aperfeiçoamento, extensão e especialização para aprimoramento de toda equipe pedagógica e dos professores especializados, além de assessorias específicas para elaboração e aplicação de referenciais de avaliação no Ensino Fundamental, formação nas áreas específicas da deficiência, dos transtornos globais do desenvolvimento e altas habilidades/superdotação e capacitação específica na formação geral realizada pela Educação Infantil, Ensino Fundamental e Ensino de Jovens e Adultos, entre outras providências formativas, como o próprio espaço dos horários coletivos no interior das escolas.
\end{abstract}

A organização curricular e didática era considerada pela SME-SP, segundo Prieto e Andrade (2009), um aspecto fundamental para o desenvolvimento da política de inclusão escolar nesse município e, portanto, uma prioridade durante o período de 2005-2012 $2^{19}$.

Nesse período, no município de São Paulo, foram realizados seminários, cursos de curta e média duração e outras ações sobre educação especial e inclusão escolar, visando à formação continuada dos profissionais da educação, particularmente os do quadro docente (Prieto et al., 2010), o que corrobora lei nacional que prevê a "valorização dos profissionais da educação", pela promoção de: "II - aperfeiçoamento profissional continuado, inclusive com licenciamento periódico remunerado para esse fim" e "V - período reservado a estudos, planejamento e avaliação, incluído na carga de trabalho" (Brasil, 1996, art. 67, p. 27.833).

As formações visavam a promover aproximações entre teorias e práticas de atendimento aos alunos com deficiência, TGD e altas habilidades/superdotação procurando apresentar e estudar fundamentações que respaldassem os professores acerca de possíveis intervenções, com vistas a fortalecer o seu processo de aprendizagem.

Para criar condições de aprimoramento, na RME-SP, a legislação possibilita diferentes composições da jornada de trabalho, com horas de efetivo trabalho com alunos e outras para o desenvolvimento das demais atribuições do seu cargo (São Paulo, 1993, art. 33 a 45) ${ }^{20}$. Lei posterior detalha que o docente, com regência de classe, poderá utilizar as horas sem os alunos para planejamento de aulas, leituras, correções de atividades e outras; também podem optar pela Jornada especial integrada de formação, na qual permanecem mais dez horas/aula na escola para estudo (São Paulo, 2007a, art. 15). Além disso, quando esses profissionais participam de cursos fora do seu horário de trabalho, estes 
podem ser revertidos em pontos, que somados permitem evolução funcional e salarial.

Quanto aos materiais de formação, Prieto et al. (2010) e Prieto e Andrade (2011) identificaram quatro produções escritas voltadas à prática dos professores que atuavam junto a alunos com deficiência, TGD e altas habilidades/superdotação: Projeto Toda Força ao $1^{\circ}$ ano - contemplando as especificidades dos alunos surdos (São Paulo, 2007b), Orientações Curriculares e Proposição de Expectativas de Aprendizagem para a Educação Infantil e o Ensino Fundamental I - LIBRAS (São Paulo, 2008a), Referencial sobre Avaliação de Aprendizagem de Alunos com Necessidades Educacionais Especiais (São Paulo, 2007b) e o Referencial sobre Avaliação da Aprendizagem na área da Deficiência Intelectual (São Paulo, 2008a) ${ }^{21}$.

Da análise das entrevistas com profissionais de dois centros especializados, apreendeu-se que esses materiais eram utilizados pelos professores especializados itinerantes nas ações de formação que desenvolviam junto aos profissionais da rede de ensino da capital paulista. Ademais, houve, no âmbito da SME-SP, oferta de curso de especialização ${ }^{22}$ em convênio com universidades e a construção de referenciais sobre avaliação da aprendizagem, e outras ofertas de centros especializados: seminários sobre a educação especial na perspectiva da educação inclusiva, cursos de curta e média duração e discussões de casos em horários coletivos.

Um aspecto a ser destacado é a atuação de professores especializados itinerantes da própria RME-SP na formação de outros professores, uma estratégia viável que otimiza recursos, mas que “[...] pode ocasionar o risco de endogenia, ou seja, os profissionais poderiam deixar de perceber e/ou de se manifestar sobre as fragilidades do programa ou projeto em avaliação" (Prieto et al., 2010, p. 90).

Além da previsão de horas adicionais na composição das jornadas de trabalho, é assegurada, na RME-SP, a formação continuada, tal como estabelecido no Estatuto do Magistério Público Municipal (São Paulo, 1992, art. $4^{\circ}$, p. 1):

A valorização dos profissionais do ensino será assegurada através de:

I - Formação permanente e sistemática de todo o pessoal do Quadro do Magistério, promovida pela Secretaria Municipal de Educação ou realizada por Universidades [...].

Considerando essa prerrogativa, foi celebrado convênio da SME-SP com a Faculdade de Filosofia e Ciências da Universidade Estadual Paulista, Campus de Marília/SP, para o oferecimento do curso Lato sensu intitulado Formação dos professores em educação especial nas áreas das deficiências auditiva, física, mental e visual, com carga horária total de 496 horas $^{23}$, com o intuito de promover condições para que professores da rede de ensino pudessem obter credenciais para atuar como especializados, seja em salas de recursos ou nos centros especializados.

Educação \& Realidade, Porto Alegre, v. 39, n. 3, p. 725-743, jul./set. 2014

Disponível em: <http://www.ufrgs.br/edu_realidade> 
De acordo com Oliveira e Drago (2012, p. 358), 200 professores participaram das duas primeiras edições desse curso, em que foram abordadas as quatro áreas de deficiência (intelectual, física, a auditiva e na área de deficiência visual), na

\begin{abstract}
[...] 3 3a edição foram contempladas as áreas da deficiência auditiva (surdez) e da intelectual e na 4 , em andamento até outubro de 2012, somente a área da deficiência intelectual, devido à demanda do próprio sistema. Em 2012, também foi estabelecida uma pareceria com o Mackenzie para formação na área da surdez.
\end{abstract}

Diante do exposto, nota-se o investimento da RME-SP em formação continuada para garantir a qualificação exigida pela legislação, considerando que se exige formação específica e que não há esses cargos previstos no Estatuto do Magistério do professorado paulistano, portanto, não há concurso de ingresso nem possibilidade de contratação para esse fim. Contudo, uma importante tarefa é proceder a avaliações para apreender como essas ações têm reverberado na construção e fortalecimento de práticas que promovam a inclusão escolar.

\title{
Potencializando o Atendimento Escolar: o Projeto Rede
}

O Projeto Rede (São Paulo, 2010) concretizava-se no município pela terceirização de serviços, uma lógica de gerenciamento da administração pública que se fortalece no Brasil nas últimas décadas ${ }^{24}$.

Nesse caso em particular, a celebração do convênio se deu entre a SME-SP e a Associação Paulista para o Desenvolvimento da Medicina $(\mathrm{SPDM})^{25}$, em grande parte para desenvolver ações que, em tese, poderiam ser instituídas no âmbito da gestão de políticas públicas municipais de articulação entre saúde e educação, tal como previa normatização de $2004^{26}$.

Com essa configuração, as ações do Projeto Rede foram desenvolvidas do segundo semestre de 2010 até, ao menos, meados de 2013 por um conjunto de profissionais. Nos registros da SME-SP/DOT-EE (São Paulo, 2012a, p. 41), até o final de 2012, havia:

\section{[...] 713 AVEs, 42 Supervisores Técnicos, sendo 21 Fisioterapeu- tas e 21 Terapeutas Ocupacionais, 13 Psicólogos, 13 Fonoaudi- ólogos, 13 Assistentes Sociais, 1 Médico fisiatra Coordenador do Núcleo, 3 Coordenadores dos Supervisores Técnicos, sen- do 2 Fisioterapeutas e 1 Terapeuta Ocupacional.}

Uma das ações desse projeto é a "prestação de serviços" pelo Auxiliar de Vida Escolar (AVE), "supervisionado pelo Supervisor Técnico" (São Paulo, 2011), cujas atividades previstas inicialmente eram a "oferta de apoio intensivo na locomoção, alimentação e higiene” (São Paulo, 2010, art. $\left.2^{\circ}, I V\right)$, e que vão assumindo contornos mais abrangentes e este profissional passa a ter que realizar a 
[...] assistência necessária nos atos de vida cotidiana (mobilidade, auxílio na questão da higiene, alimentação, medicamento, recreio, atividades dentro e fora das salas) e outras que se fizerem necessárias para participação ativa do aluno na rotina escolar e aquelas extra-curriculares realizadas pelas escolas (São Paulo, 2012a, p. 40).

Seis outras ações desse projeto, a serem desempenhadas pelos profissionais supracitados, constam no referido documento (São Paulo, 2012a, p. 40), a saber: dar suporte técnico aos AVEs e "equipes escolares a fim de sanar as situações adversas inerentes ao processo de inclusão"; realizar avaliação funcional dos alunos público-alvo da educação especial com a indicação de recursos de tecnologia assistiva, quando necessário; promover a regulação com os serviços de saúde com vistas a intermediar, por meio do "serviços de assistência social", as redes de saúde e educacionais para prover o "atendimento clínico e/ou terapêutico" desse alunado; "complementar a avaliação pedagógica", fazendo avaliação dos alunos; e, ainda, assessorar as escolas para a indicação de tecnologia assistiva, cuidar da produção de materiais orientadores para os AVEs, supervisor técnico, pais e professores, bem como prover formação dos profissionais da escola e dos pais, incluindo "AVEs, professores, gestores e funcionários e organizar atividades de formação para os pais".

Constata-se, assim, pelos documentos, que o AVE é um agente que adentra aos muros da escola, mas seus vínculos parecem ser predominantemente com os profissionais da instituição conveniada, em particular com o seu supervisor técnico, um profissional da área da saúde. Ambos têm respaldo do núcleo multidisciplinar ligado à SPDM (São Paulo, 2011, art. $5^{\circ}$ ). Cabe registrar questionamentos quanto a como (e se) o caráter educacional de seu trabalho estava sendo assegurado, posto que o(s) aluno(s) a quem os AVEs prestavam seus serviços estavam em um ambiente que tem por função essencial ser um constante espaço formativo.

Pela Portaria n. 5.594 de 2011, foram estabelecidas como atribuições do AVE desde a recepção do aluno na escola até o auxílio a este em relação a higiene, alimentação, medicação e recreação (São Paulo, 2011) e, em seu art. $3^{\circ}$, inciso X, estabelece que deva aguardar do lado de fora da sala de aula até ser solicitado para executar suas funções, "[...] exceto no caso de haver solicitação do professor ou da equipe gestora, para acompanhar o aluno na sala de aula, durante o desenvolvimento das atividades escolares (exclusivamente no que se refere aos cuidados do aluno)". Essa descrição é complementada por parágrafo único que estabelece: "[...] observadas as características de cada Unidade Educacional, atender, em média, 04 (quatro) alunos por período" (São Paulo, 2011, art. 3º).

Em 2013, fica estabelecido que a indicação do AVE ocorreria apenas após avaliação de sua necessidade feita pela equipe escolar, juntamente com a família, supervisor escolar e equipe do centro especializado, que devem reavaliar a situação periodicamente (São Paulo, 2013, art. 5º). 
Esse procedimento busca combater distorções que podem ocorrer com a previsão de contratação desses profissionais em escolas com matrículas de alunos público-alvo da educação especial: uma refere-se à sua desnecessária indicação e, outra, a de que eles sejam instados a assumir responsabilidades que não lhes compete em relação à escolarização desse alunado.

Essas duas possibilidades, inclusive, estiveram presentes nas falas dos profissionais dos centros especializados nos encontros mensais, que explicitavam a necessidade de retomar constantemente com os profissionais das escolas em que faziam itinerância os papéis a serem desempenhados pelos AVEs, pois constatavam que muitos reivindicavam estes profissionais independentemente das características do aluno, que, pela legislação, deveria requerer apoio intensivos e contínuos.

No entanto, também se deve investir na formação dos AVEs para que não extrapolem suas atribuições. Porém, diferentemente dos estagiários, essa ação não é responsabilidade dos profissionais dos centros especializados, pois sua intervenção, neste caso, circunscreve-se a: "III - formalizar, por meio de protocolo específico a solicitação de AVE ratificando a sua necessidade" e "IV - indicar a necessidade de remanejamento dos AVEs e definir a Unidade Educacional de exercício" (São Paulo, 2013, art. $6^{\circ}$ ).

Em face às considerações e análises dos projetos explorados Apoiar, Formar e Rede - pode-se apreender movimentos do município para propor e entrelaçar ações a partir de uma avaliação de necessidades feita por grupo de profissionais de vários setores da SME-SP, o que pode ser avaliado como bastante salutar. Entretanto, como foi registrado em vários momentos, não foram localizadas avaliações ${ }^{27}$ sobre essas ações que captassem suas interferências na escolarização do público-alvo a que se destinam, considerando que “[...] a avaliação institucional e de políticas públicas torna-se mais relevante quando pode oferecer informações não apenas sobre impacto, mas sobre resultados ou consequências mais amplas e difusas das ações desenvolvidas" (Belloni; Magalhães; Sousa, 2001, p. 9, grifos dos autores).

\section{Reflexões sobre o Construído e o por Construir}

A elaboração deste artigo permitiu sistematizar a implementação da educação especial paulistana, resgatando uma história que permite concluir que esse município toma como sua responsabilidade a orientação inclusiva e que o Programa Inclui, que está em vigor, resulta de uma sequência de investimentos políticos, financeiros e pedagógicos com vistas à sua consolidação.

Observa-se que, buscando atender a compromissos firmados na etapa inicial de implantação da política de educação especial no município de São Paulo, foram estabelecidas metas, dentre elas: a garantia de formação especializada tendo como foco as necessidades dos alunos,

736 Educação \& Realidade, Porto Alegre, v. 39, n. 3, p. 725-743, jul./set. 2014 Disponível em: <http://www.ufrgs.br/edu_realidade> 
oferta de formação continuada e disponibilização de materiais de apoio ao professor; portanto, no que se refere à formação, houve aumento no número de cursos, encontros e seminários destinados aos profissionais da educação no município de São Paulo.

Todavia, destaca-se a necessidade, por parte dos centros especializados, de desenvolver estratégias de registro e sistematização de dados, o que permitiria analisar os efeitos das ações de formação no âmbito das escolas, das salas de aula e na aprendizagem dos alunos com deficiência, TGD e altas habilidades/superdotação matriculados em classe comum. Ainda, é preciso que o sistema de ensino invista também na formação continuada dos profissionais dos centros especializados e dos professores das salas de recursos.

A previsão, em documento legal, de AVE em escolas que tenham matriculados alunos com deficiência e TGD dá clareza sobre quem deveria ser responsável por auxiliar o aluno no ambiente escolar, eliminando, assim, a necessidade de se negociar tais atividades com funcionários da U.E. ou mesmo com familiares dos estudantes, que não têm autonomia para exercer essas atribuições.

Ao pensar na contratação de estagiários, devem ser considerados alguns riscos, dentre eles, que lhes seja delegada a função de tutorar o aluno com deficiência ou TGD, desresponsabilizando o regente da classe comum pelo planejamento do ensino e desenvolvimento das atividades com a turma, tendo em vista assegurar a participação de todos os alunos.

Um aspecto a ser destacado a partir dos resultados deste trabalho é a necessidade do diálogo constante com os profissionais que estão nas escolas e com os gestores, a fim de buscar caminhos para aprimorar a política em implantação. Para isso, não se pode prescindir de avaliações que indiquem qual tem sido a resposta ao principal objetivo proposto: garantir aos alunos com deficiência, TGD e altas habilidades/superdotação acesso à educação e permanência com aprendizagem.

Faz-se necessário assegurar e consolidar intervenções de formação continuada para os diferentes participantes da comunidade escolar com a participação dos gestores das escolas, professores de classes comuns e de serviços de educação especial, funcionários técnico-administrativos, estagiários e AVEs, pois todos precisam, mais e mais, compreender o(s) seu(s) papel(éis) diante desses estudantes. Além disso, é preciso aprimorar mecanismos de monitoramento das políticas para que sejam identificadas as distorções e necessidades de aprimoramento e sejam organizadas intervenções mais específicas onde forem constatados deslocamentos de atribuições. 


\section{Notas}

1 População a que se dirigem as políticas de educação especial no Brasil, tal como estabelecido pela Lei n. 12.796 de 2013 (Brasil, 2013).

2 Segundo Prieto (2000), as três gestões municipais (Jânio - 1986/1988; Luiza Erundina - 1989/1992; Paulo Maluf - 1993/1996) a que se remeteu sua pesquisa apresentavam como princípio norteador a integração desse alunado, e cada administração apresentou um tipo de programa, embora a oferta de atendimento tenha se concretizado pela oferta de serviço organizado nos moldes de salas de recursos, com diferentes denominações (Classe de educação especial, em 1987; Centro público de apoio e projetos e Centro de treinamento e apoio, ambas de 1992; Sala de atendimento aos portadores de necessidades especiais, em 1993) (Prieto, 2000).

3 Emanadas pela Constituição Federal de 1988, Lei de Diretrizes e Bases da Educação Nacional de 1996, Resolução CNE/CEB n. 2 de 2001, Política Nacional de Educação Especial na Perspectiva da Educação Inclusiva de 2008, Decreto n. 6.949 de 2009 e Decreto n. 7.611 de 2011.

4 Doravante centros especializados.

5 Para fins deste trabalho, serão denominados professores especializados itinerantes.

6 Também denominada, neste trabalho, sala de recursos.

7 Exceto em relação às escolas de surdos em que o total se manteve desde 2004, constatou-se certa variação dos demais quantitativos a depender da fonte consultada.

8 Trata-se de relatório intitulado Programa Inclui, de autoria da Diretoria de Orientação Técnica - Educação Especial, obtido via solicitação oficial à SME-SP, aqui denominado Relatório Inclui.

9 Os dados do referido relatório não especificam em qual Diretoria Regional de Educação-DRE - os professores especializados itinerantes foram designados.

10 Os professores especializados itinerantes têm suas designações renovadas ano a ano.

11 Para entender os desafios impostos à gestão da política nesse município, na região do Centro A havia, em 2010, 317 unidades educacionais. Dessas, 40 eram escolas de educação infantil e 62 escolas de ensino fundamental e 208.202 alunos, dos quais 1412 tinham demanda relacionada à educação especial. A equipe do Centro era composta por uma coordenadora, com formação em deficiência auditiva, que, por vezes, também realizava serviço itinerante, e quatro professoras especializadas itinerantes, uma de cada área da deficiência (intelectual-DI-, auditiva-DA-, visual-DV-e física-DF). Nas escolas, havia 17 salas de recursos (SR) criadas e 15 em funcionamento (11 SR/DI, uma SR/ DA, uma SR/DV e duas SR/DF).

12 Trata-se do Auxiliar de Vida Escolar. A ser retomado em momento oportuno.

13 Havia registro de 159 salas de recursos, mas sete constavam como revogadas. Ademais, registre-se que sobre quatro das 152 havia observação de que estavam sem professor e uma revogada, embora não desativada, no início de 2013, quando do envio da planilha pela SME-SP/DOT-P.

14 Desse total, oito estavam registradas sem professor na mesma planilha.

738 Educação \& Realidade, Porto Alegre, v. 39, n. 3, p. 725-743, jul./set. 2014 Disponível em: <http://www.ufrgs.br/edu_realidade> 
15 Duas sem professor e, em uma sala, o atendimento estava suspenso porque a professora estava em licença gestante. Este fato revela que a SME-SP não tinha, para as salas de recursos, profissionais para dar continuidade ao atendimento dos alunos quando seu regente estava afastado por algum motivo.

16 Com quatro salas sem professor.

17 Não há informação no mesmo relatório quanto às DRE em que foram instaladas as salas de recursos.

18 Expressão ainda muito utilizada na rede para identificar esse alunado elegível para os atendimentos na modalidade de educação especial.

19 No biênio 2005-2006, José Serra foi o prefeito e Gilberto Kassab o vice-prefeito; na segunda etapa do mandato - 2007-2008 -, Serra saiu para concorrer a governador do estado de São Paulo e Kassab assumiu a Prefeitura Municipal de São Paulo até o final de 2012, após sua recondução em novo pleito.

20 No município de São Paulo, os professores titular e adjunto podem ter suas jornadas denominadas de: "a) Jornada Básica" e "b) Jornada Especial Ampliada e Jornada Especial Integral”. Art. 36 - "A Jornada Especial Ampliada corresponde a 25 (vinte e cinco) horas-aula e 5 (cinco) horas atividade semanais, perfazendo 180 (cento e oitenta) horas-aula mensais". Art. 37 - "A Jornada Especial Integral corresponde a 25 (vinte e cinco) horas-aula e 15 (quinze) horas adicionais semanais, perfazendo 240 (duzentos e quarenta) horas-aula mensais". (São Paulo, 1993).

21 Em 2012, foi publicado o Referencial sobre Avaliação da Aprendizagem na área da Deficiência Intelectual do ciclo II e Educação de Jovens e Adultos (EJA). Todos esses materiais se encontram disponíveis no Portal SME-SP: <http://www. portalsme.prefeitura.sp.gov.br>.

22 Houve três edições do curso por meio de convênio com a Universidade Estadual Paulista Júlio de Mesquita Filho (Unesp) - em 2007, 2008, 2010 - contemplando diferentes deficiências em cada ano. Em 2012, manteve-se esse convênio apenas para formação em deficiência intelectual e foi firmado outro entre a RME-SP com o Mackenzie para formar professores na área da deficiência auditiva.

23 O primeiro dos convênios foi divulgado no Comunicado n. 1.171 de 2007 (São Paulo, 2007c).

24 Terceirização na administração pública aqui é entendida como transferência para a iniciativa privada de atividades que deveriam ser exercidas pelo Estado.

25 No site dessa instituição, contudo, não constam informações sobre a referida parceria, mas a apresenta da seguinte forma: "A SPDM é uma das maiores entidades filantrópicas de saúde do Brasil - com cerca de 40.000 colaboradores, atuando em nove estados e 28 municípios, com a vocação de contribuir para a melhoria dos serviços médicos prestados à população. Gerencia unidades hospitalares e ambulatoriais construídas e equipadas pelo Estado e por alguns municípios, com o objetivo de levar o que há de mais avançado em conhecimento médico para as populações mais necessitadas, além de ser um posto avançado de capacitação de recursos humanos". Disponível em: <http://www. spdm.org.br/site/pt/quem-somos.html>. Acesso em: 6 jun. 2013.

26 Trata-se de Portaria intersecretarial n. 22 de 2004, que não foi implantada, mas visava a "[...] instituir um Grupo Intersecretarial de Apoio a Inclusão no âmbito de cada Subprefeitura do Município de São Paulo, [...] constituído necessariamente por representantes das Coordenadorias de Educação, da Saúde e da Assistência Social das Subprefeituras" (São Paulo, 2004c, caput e art. 1º).

Educação \& Realidade, Porto Alegre, v. 39, n. 3, p. 725-743, jul./set. 2014.

Disponível em: <http://www.ufrgs.br/edu_realidade> 
27 Avaliação é aqui “[...] entendida como um processo sistemático de análise de uma atividade, fatos ou coisas que permite compreender, de forma contextualizada, todas as suas dimensões e implicações, com vistas a estimular seu aperfeiçoamento" (Belloni; Magalhães; Sousa, 2001, p. 15, grifos dos autores).

\section{Referências}

BAPTISTA, Claudio Roberto; JESUS, Denise Meyrelles de (Org.). Avanços em Políticas de Inclusão: o contexto da educação especial no Brasil e em outros países. 2. ed. Porto Alegre: Editora Medição, 2011.

BARDIN, Laurence. Análise de Conteúdo. Lisboa: Edições 70, LDA, 2009.

BELLONI, Isaura; MAGALHÃES, Heitor de; SOUSA, Luzia Costa. Metodologia de Avaliação em Políticas Públicas. 2. ed. São Paulo: Cortez Editora, 2001. (Coleção Questões da Nossa Época; v. 75).

BRASIL. Constituição da República Federativa do Brasil. Brasília: Senado, 1988. BRASIL. Lei n. 9.394, de 20 de dezembro de 1996. Estabelece as Diretrizes e Bases da Educação Nacional. Brasília. Diário Oficial da União, Brasília, 23 dez. 1996. Seção 1, p. 27.833. Disponível em: <http://portal.mec.gov.br/seed/arquivos/pdf/tvescola/leis/lein9394.pdf>. Acesso em: 10 abr. 2011.

BRASIL. Ministério da Educação. Resolução CNE/CEB n. 2. Diretrizes Nacionais para a Educação Especial na Educação Básica, de 11 de setembro de 2001. Diário Oficial da União, Brasília, 14 set. 2001. Seção 1E, p. 39-40. Disponível em: <http://portal.mec.gov.br/seesp/arquivos/pdf/res2_b.pdf >. Acesso em: 10 jan. 2011.

BRASIL. Secretaria de Educação Especial. Política Nacional de Educação Especial na perspectiva da educação inclusiva. Inclusão: Revista da Educação Especial, Brasília, v. 4, n. 1, p. 9-17, jan./jul. 2008.

BRASIL. Decreto n. 6.949, de 25 de agosto de 2009. Promulga a Convenção Internacional sobre os Direitos das Pessoas com Deficiência e seu Protocolo Facultativo, assinados em Nova York, em 30 de março de 2007. Diário Oficial da União, Brasília, 26 ago. 2009. Brasília, DF, 2009. Disponível em: <http://www.planalto.gov.br/ ccivil_03/_ato2007-2010/2009/decreto/d6949.htm>. Acesso em: 20 fev. 2012.

BRASIL. Decreto n. 7.611, de 17 de novembro de 2011. Dispõe sobre a educação especial, o atendimento educacional especializado e dá outras providências. Brasília, 2011a. Diário Oficial da União, Brasília, 18 nov. 2011. Seção 1, p. 12. Disponível em: <http://www.planalto.gov.br/ccivil_03/_Ato2011-2014/2011/Decreto/D7611.htm>. Acesso em: 20 fev. 2012.

IBIAPINA, Ivana Maria Lopes de Melo. Pesquisa Colaborativa: investigação, formação e produção de conhecimento. Brasília: Líder Livro Editora, 2008.

JESUS, Denise Meyrelles de; BAPTISTA, Claudio Roberto; BARRETO, Maria Aparecida Santos Corrêa; VICTOR, Sonia Lopes (Org.). Inclusão, Práticas Pedagógicas e Trajetórias de Pesquisa. 2. ed. Porto Alegre: Editora Mediação, 2009.

MANTOAN, Maria Teresa Eglér (Org.). Caminhos Pedagógicos da Inclusão. Como estamos implementando a educação (de qualidade) para todas as escolas brasileiras. São Paulo: Memnon, 2001.

MANTOAN, Maria Teresa Eglér. Inclusão Escolar. O que é? Por quê? Como fazer? São Paulo: Moderna, 2003.

MAZZOTTA, Marcos José da Silveira; SOUSA, Sandra Maria Zakia Lian. Inclusão Escolar e Educação Especial: considerações sobre a política educacional 
brasileira. Estilos da Clínica, Instituto de Psicologia da Universidade de São Paulo, v. 5, n. 9, p. 96-108, 2000.

MAZZOTTA, Marcos José da Silveira. Educação Especial no Brasil: história e políticas públicas. São Paulo: Cortez Editor, 1996.

MINAYO, Maria Cecília de Souza. O Desafio do Conhecimento: pesquisa qualitativa em saúde. 10. ed. São Paulo: HUCITE, 2007.

MIRANDA, Marilia Gouvea de; RESENDE, Anita C. Azevedo. Sobre a Pesquisa-Ação na Educação e as Armadilhas do Praticismo. Revista Brasileira de Educação, Rio de Janeiro, v. 11, n. 33, p. 511-518, set./dez. 2006.

OLIVEIRA, Anna Augusta Sampaio de; DRAGO, Silvana Lucena dos Santos. A Gestão da Inclusão Escolar na Rede Municipal de São Paulo: algumas considerações sobre o Programa Inclui. Ensaio: avaliação de políticas públicas em educação, Rio de Janeiro, v. 20, n. 75, p. 347-372, 2012.

PRIETO, Rosângela Gavioli. Política Educacional do Município de São Paulo: estudo sobre o atendimento de alunos com necessidades educacionais especiais no período de 1986 a 1996. 2000. 260 f. Tese (Doutorado em Educação) - Faculdade de Educação, Universidade de São Paulo, São Paulo, 2000.

PRIETO, Rosângela Gavioli. Atendimento Escolar de Alunos com Necessidades Educacionais Especiais: um olhar sobre as políticas públicas de educação no Brasil. In: ARANTES, Valéria Amorim (Org.). Inclusão Escolar: pontos e contrapontos. 1. ed. São Paulo: Summus, 2006. P. 31-73.

PRIETO, Rosângela Gavioli; ANDRADE, Simone Girardi. A Inclusão da Formação de Professores na Inclusão Escolar: um estudo de política municipal. In: V SEMINÁRIO NACIONAL DE PESQUISA EM EDUCAÇÃO ESPECIAL: formação de professores em foco. Anais... Rio Grande do Sul, 2009. 1 CD-Rom.

PRIETO, Rosângela Gavioli et al. Atendimento Escolar de Alunos com Necessidades Educacionais Especiais: análise das ações dos Centros de Formação e Acompanhamento à Inclusão (Cefai). Feusp/Fapesp, jul. 2010.

PRIETO, Rosângela Gavioli; ANDRADE, Simone Girardi. A Inclusão da Formação de Professores na Inclusão Escolar: um estudo de política municipal. In: CAIADO, Katia Regina M.; JESUS, Denise Meyrelles de; BAPTISTA, Cláudio Roberto. Professores e Educação Especial: formação em foco. Porto Alegre: Mediação/CDV/ FACITEC, 2011. P. 91-110.

RODRIGUES, Davi. Inclusão e Educação: doze olhares sobre a educação inclusiva. São Paulo: Summus Editorial, 2006.

SÃO PAULO (município). Lei n. 11.229, de 26 de junho 1992. Dispõe sobre o Estatuto do Magistério Público Municipal, e dá outras providências. 1992. Diário Oficial da Cidade de São Paulo, São Paulo, 27 jun. 1992. P. 1.

SÃO PAULO (município). Lei n. 11.434, de 12 de novembro 1993. Dispõe sobre a organização dos Quadros dos Profissionais de Educação, da Prefeitura do Município de São Paulo, e dá outras providências. 1993. Diário Oficial da Cidade de São Paulo, São Paulo, 13 nov. 1993. P. 1.

SÃO PAULO (município). Decreto n. 45.415, de 18 de outubro de 2004 que estabelece diretrizes para a Política de atendimento a crianças, adolescentes, jovens e adultos com necessidades educacionais especiais no sistema municipal de ensino. 2004a. Diário Oficial da Cidade de São Paulo, São Paulo, 19 out. 2004. P. 1. SÃO PAULO (município). Portaria n. 5.718, de 17 de dezembro de 2004 a qual dispõe sobre a regulamentação do Decreto n. 45.415, de 18/10/04, que estabelece diretrizes para a Política de atendimento a crianças, adolescentes, jovens

Educação \& Realidade, Porto Alegre, v. 39, n. 3, p. 725-743, jul./set. 2014.

Disponível em: <http://www.ufrgs.br/edu_realidade> 
Educação Especial e Inclusão Escolar

e adultos com necessidades educacionais especiais no sistema municipal de ensino, e dá outras providências. 2004b. Diário Oficial da Cidade de São Paulo, São Paulo, 18 dez. 2004. P. 15.

SÃO PAULO (município). Portaria intersecretarial n. 22, de 10 de dezembro de 2004. 2004c. Diário Oficial da Cidade de São Paulo, São Paulo, 23 dez. 2004. P. 1.

SÃO PAULO (município). Secretaria Municipal de Educação. Diretoria de orientação técnica. Projeto Toda Força ao $1^{\circ}$ Ano: contemplando as especificidades dos alunos surdos. Secretaria Municipal de Educação São Paulo, Secretaria Municipal de Educação. São Paulo: SME/DOT 2007a. Disponível em: <http:// portalsme.prefeitura.sp.gov.br/Documentos/BibliPed/EnsFundMedio/CicloI/ Tof/TofPrimeiro\%20Ano_ContemplandoEspecificidades_dos_Alunos_Surdos. pdf>. Acesso em: 20 dez. 2012.

SÃO PAULO (município). Secretaria Municipal de Educação. Diretoria de orientação técnica. Referencial Sobre Avaliação da Aprendizagem de Alunos com Necessidades Educacionais Especiais. São Paulo: SME/DOT, 2007b. Disponível em: <http://portalsme.prefeitura.sp.gov.br/Documentos/BibliPed/EdEspecial/Referencial_AvaliacaoAprendizagem_NecessidadesEspeciais.pdf $>$. Acesso em: 20 dez. 2012.

SÃO PAULO (município). Secretaria Municipal de Educação. Comunicado n. 1.171, de 5 de julho de 2007. Divulga abertura de inscrições para o curso de pós-graduação lato sensu "Formação dos Professores em Educação Especial nas Âreas das Deficiências Auditiva, Física, Mental e Visual". 2007c. Diário Oficial da Cidade de São Paulo, São Paulo, 6 jul. 2007. P. 36. Disponível em: <http:// www.sinpeem.com.br/lermais_materias.php?cd_materias=1212>. Acesso em: 20 jan. 2012.

SÃO PAULO (município). Secretaria Municipal de Educação. Diretoria de orientação técnica. Referencial sobre Avaliação da Aprendizagem na Área da Deficiência Intelectual. Secretaria Municipal de Educação. São Paulo: SME/DOT, 2008a. Disponível em: <http://portalsme.prefeitura.sp.gov.br/Documentos/ BibliPed/EdEspecial/Referencial_AvaliacaoAprendizagem_DeficienciaIntelectual.pdf $>$. Acesso em: 15 maio 2011.

SÃO PAULO (município). Secretaria Municipal de Educação. Diretoria de orientação técnica. Orientações Curriculares e Proposição de Expectativas de Aprendizagem para Educação Infantil e Ensino Fundamental: Libras, 2008b. São Paulo, 2008. Disponível em: <http://portalsme.prefeitura.sp.gov.br/Documentos/BibliPed/EdEspecial/OrientCurriculares_ExpectativasAprendizagem_Ednfantil_EnsFund_LPO_Surdos.pdf>. Acesso em: 15 maio 2011.

SÃO PAULO (município). Secretaria Municipal de Educação. Decreto n. 51.778, de 14 de setembro de 2010. Institui a Política de Atendimento de Educação Especial, por meio do Programa Inclui, no âmbito da Secretaria Municipal de Educação. Secretaria Municipal de Educação. São Paulo: SME/DOT, 2010. Diário Oficial da Cidade de São Paulo, São Paulo, 15 set. 2010. P. 1.

SÃO PAULO (município). Portaria n. 5.594, de 28 de novembro de 2011. Especifica as competências dos profissionais envolvidos no Projeto Rede, integrante do Programa Inclui, instituído pelo Decreto n. 51.778, de 14/09/10 e dá outras providências. Diário Oficial da Cidade de São Paulo, São Paulo, 29 nov. 2011. P. 14.

SÃO PAULO (município). São Paulo: SME/DOT. Programa Inclui. Secretaria Municipal de Educação. São Paulo: Mimeografado, 2012a.

SÃO PAULO (município). Secretaria Municipal de Educação. Portaria n. 2.496, de 2 de abril de 2012. Regulamenta as Salas de apoio e acompanhamento à in- 
clusão - SAAIs integrantes do inciso II do artigo $2^{\circ}$ - Projeto apoiar que compõe o Decreto no 51.778 , de 14/09/10, que instituiu a política de atendimento de educação especial do Programa Inclui, no âmbito da Secretaria Municipal de Educação de São Paulo. São Paulo: SME/DOT, 2012b. Diário Oficial da Cidade de São Paulo, São Paulo, 3 abr. 2012.

SÃO PAULO (município). Portaria n. 2.963, de 15 de maio de 2013. Organiza o quadro de auxiliares de vida escolar (AVEs) e de estagiários de Pedagogia, em apoio a educação inclusiva, especifica suas funções e dá outras providências. 2013. Diário Oficial da Cidade de São Paulo, São Paulo, 16 maio 2013.

Rosângela Gavioli Prieto é professora doutora da Faculdade de educação da Universidade de São Paulo e atua no ensino, pesquisa e extensão com políticas de educação especial. Coordena o Laboratório didático de educação especial - Ladesp -, o Centro de ensino e pesquisas da e sobre a Língua brasileira de sinais - CesLibras - no âmbito da Feusp, e o GT 15 Educação especial da Associação Nacional de Pós-graduação e Pesquisa em Educação - Anped.

E-mail: rosangel@usp.br

Karina Soledad Maldonado Molina Pagnez é professora doutora da Faculdade de educação da Universidade de São Paulo, no departamento de Metodologia do Ensino e Educação Comparada. Atua no ensino, pesquisa e extensão com formação de professores para a educação especial. Coordenadora da área de educação especial no curso de pós-graduação em Educação na Feusp.

E-mail:kpagnez@usp.br

Roseli Kubo Gonzalez é pedagoga, mestre e doutora em educação pela Faculdade de educação da Universidade de São Paulo (Feusp). Atualmente trabalha com formação de professores e, também, desenvolve atividades de pesquisa junto ao Laboratório didático de educação especial (Ladesp) da Feusp.

E-mail:rkg@usp.br 